\title{
Using an ultraviolet cabinet improves compliance with the World Health Organization's hand hygiene recommendations by undergraduate medical students: a randomized controlled trial
}

Sandrine Dray ${ }^{1}$, Samuel Lehingue ${ }^{1}$, Sabine Valera ${ }^{1}$, Philippe Nouguier ${ }^{2}$, Michel Salah Boussen ${ }^{3}$, Florence Daviet ${ }^{1}$, Delphine Bastian ${ }^{1,4}$, Estelle Pilarczik ${ }^{1,4}$, Isabelle Jousset ${ }^{1}$, Sébastien Le Floch ${ }^{1}$, Georgette Grech ${ }^{5}$, Georges Leonetti ${ }^{6}$, Laurent Papazian ${ }^{1,7}$, Nadim Cassir ${ }^{5}$ and Jean-Marie Forel ${ }^{1,7^{*}}$ (D)

\begin{abstract}
Background: Appropriate hand hygiene $(H H)$ is key to reducing healthcare-acquired infections. The World Health Organization (WHO) recommends education and training to improve HH knowledge and compliance. Physicians are ranked among the worst of all healthcare workers for compliant handrubbing with its origin probably being the failure to learn this essential behavior during undergraduate medical studies. This study evaluated if the use of Ultraviolet-cabinets (UVC) for fluorescent-alcohol-based handrubs (AHR) during an undergraduate medical student training improved the compliance rate to the $\mathrm{WHO}$ hand hygiene recommendations (completeness of AHR application and $\mathrm{HH}$ opportunities).

Methods: This randomized trial compared a HH training with personal feedback (using UVc) to a control group. The first year, the students (2nd degree) were convened by groups (clusters) of 6-9 for a demonstration of the correct execution of WHO procedure. Randomization by cluster was done prior $\mathrm{HH}$ training. In the control group, the students hand rubbed under visual supervision of a tutor. In the intervention group after the same visual supervision, completeness of fluorescent-AHR hand application was recorded under UVc and was shown to the student. The intervention group had free access to the UVc until complete application. HH practices were included in simulation sessions for the both groups. One year after (3rd degree), all the students were asked to hand rub with fluorescent-AHR. A tutor (blinded to the study group) assessed the completeness of hand application under UVc and the compliance with the WHO opportunities. Complete application of AHR was defined as fluorescence for all the surfaces of hands and wrists.

(Continued on next page)
\end{abstract}

\footnotetext{
* Correspondence: jean-marie.forel@ap-hm.fr

'Médecine Intensive Réanimation, Assistance Publique Hôpitaux de Marseille, CHU Nord, Chemin des Bourrely, 13015 Marseille, France

${ }^{7}$ Faculté de Médecine de Marseille, EA 3279, CEReSS - Health Service Research and Quality of life Center, Aix Marseille University, Marseille, France Full list of author information is available at the end of the article
}

(c) The Author(s). 2020 Open Access This article is licensed under a Creative Commons Attribution 4.0 International License, which permits use, sharing, adaptation, distribution and reproduction in any medium or format, as long as you give appropriate credit to the original author(s) and the source, provide a link to the Creative Commons licence, and indicate if changes were made. The images or other third party material in this article are included in the article's Creative Commons licence, unless indicated otherwise in a credit line to the material. If material is not included in the article's Creative Commons licence and your intended use is not permitted by statutory regulation or exceeds the permitted use, you will need to obtain permission directly from the copyright holder. To view a copy of this licence, visit http://creativecommons.org/licenses/by/4.0/. The Creative Commons Public Domain Dedication waiver (http://creativecommons.org/publicdomain/zero/1.0/) applies to the data made available in this article, unless otherwise stated in a credit line to the data. 
(Continued from previous page)

Results: 242 students participated (140 in the intervention group and 102 in the control group). One year after the initial training, the rate of complete application of AHR was doubled in the intervention group (60.0\% vs. 30.4\%, $p<0.001)$. In a multivariate analysis which included gender, additional HH or UVc training, surgical traineeship and regular use of AHR, the hazard ratio for the intervention was 3.84 (95\%Cl: 2.09-7.06). The compliance with the HH WHO's opportunities was increased in the intervention group (58.1\% vs. 42.4\%, $p<0.018)$.

Conclusion: Using UVc for undergraduate medical students education to hand hygiene improves their technique and compliance with WHO recommendations.

Keywords: Hand hygiene, Education, Infection prevention, Alcohol-based handrubs, Ultraviolet-cabinets, Medical student, Health simulation

\section{Background}

Appropriate hand hygiene $(\mathrm{HH})$ is key to both preventing pathogen transmissions and reducing healthcare-acquired infections. Recently, SARS Cov-2 transmission highlights the importance of hand hygiene. The World Health Organization (WHO) recommends education and training as part of a multimodal strategy to improve $\mathrm{HH}$ knowledge and handrubbing compliance. Physicians are ranked among the worst of all healthcare workers (HCW) for compliant handrubbing $[1,2]$ with its origin probably being the failure to learn this essential behavior during undergraduate medical studies. Despite the fact that past studies recommended an increased emphasis on $\mathrm{HH}$ in undergraduate teaching [1-5], very few studies to date explore the development and testing of $\mathrm{HH}$ education modules, particularly for the youngest medical students [6-8]. The focus is more on being compliant with $\mathrm{HH}$ indications than $\mathrm{HH}$ techniques. While compliant handrubbing for nosocomial infection prevention is more preponderant, poorly performed $\mathrm{HH}$ may also lead to pathogen transmission as outlined in the "how to handrub" section of the WHO guidelines [9]. These guidelines use an ultraviolet (UV) light inspection cabinet among the pedagogical tools to enhance alcoholbased handrubs (AHR). Supervised personal feedback states that the use of UV improves performance of the technique for short-term periods in medical and nursing students [10-13]. However, to the best of our knowledge, no randomized controlled trial (RCT) has evaluated such a strategy. Moreover, the long-term effects of these educational programs is poorly analyzed.

The aim of the present study was to evaluate, in a RCT, the long-term (one year) contribution of supervised personal feedback using UV light inspection cabinets in a $\mathrm{HH}$ education program for pre-internship second and third year undergraduate medical students.

Our main hypothesis was that the use of a supervised personal feedback for fluorescent AHR using a UV cabinet during the first year program would increase the rate of complete AHR handrubbing on the 2nd year. Our secondary hypothesis was that this could enhance compliant handrubbing according to WHO's $\mathrm{HH}$ opportunities during simulation scenario-based learning activities in the second year of medical training.

\section{Methods}

This study was a cluster randomized trial in two parallel groups comparing training with supervised personal feedback using UV cabinet to a control group (without UV). The study was conducted between November 2015 and May 2017 during two years of a medical training program. This program was mandatory for second and third year undergraduate medical students prior to their internship at the Aix-Marseille University. The study was approved by our Institutional Review Board. An informed consent from each participant was required. Twenty students refused to participate. The study's design is described in Fig. 1.

During the first year, and prior to their first simulation session, medical students had digital work station access to online PowerPoint slides as well as a short video extracted from the "WHO tools and resources" [14, 15]. The first module of the program occurred prior to their in-hospital traineeship. Simulation sessions by groups of six to nine students were set up to enhance learning $\mathrm{HH}$ practices. This was achieved via simulation scenariobased learning activities on common medical acts (insertion of a peripheral vascular catheter during the first year training and an arterial puncture during the second year training). The first module was partitioned into the four following steps: 1) a short lecture on the basics of $\mathrm{HH}, 2)$ an Infection Control Department tutor demonstrating the correct execution of WHO's six-step $\mathrm{HH}$ procedures (Additional File 1), 3) $\mathrm{HH}$ training on AHR correct technique and finally, 4) a simulation scenario based on learning a peripheral vascular catheter insertion showing $\mathrm{HH}$ objectives and opportunities ("the five moments for $\mathrm{HH}$ in health care of WHO" i.e. before touching a patient, before clean/aseptic procedures, after body fluid exposure/risk, after touching a patient, and after touching patient surroundings) translated into practice. After the same $\mathrm{HH}$ review and demonstration the training differed between the two groups as follows: 


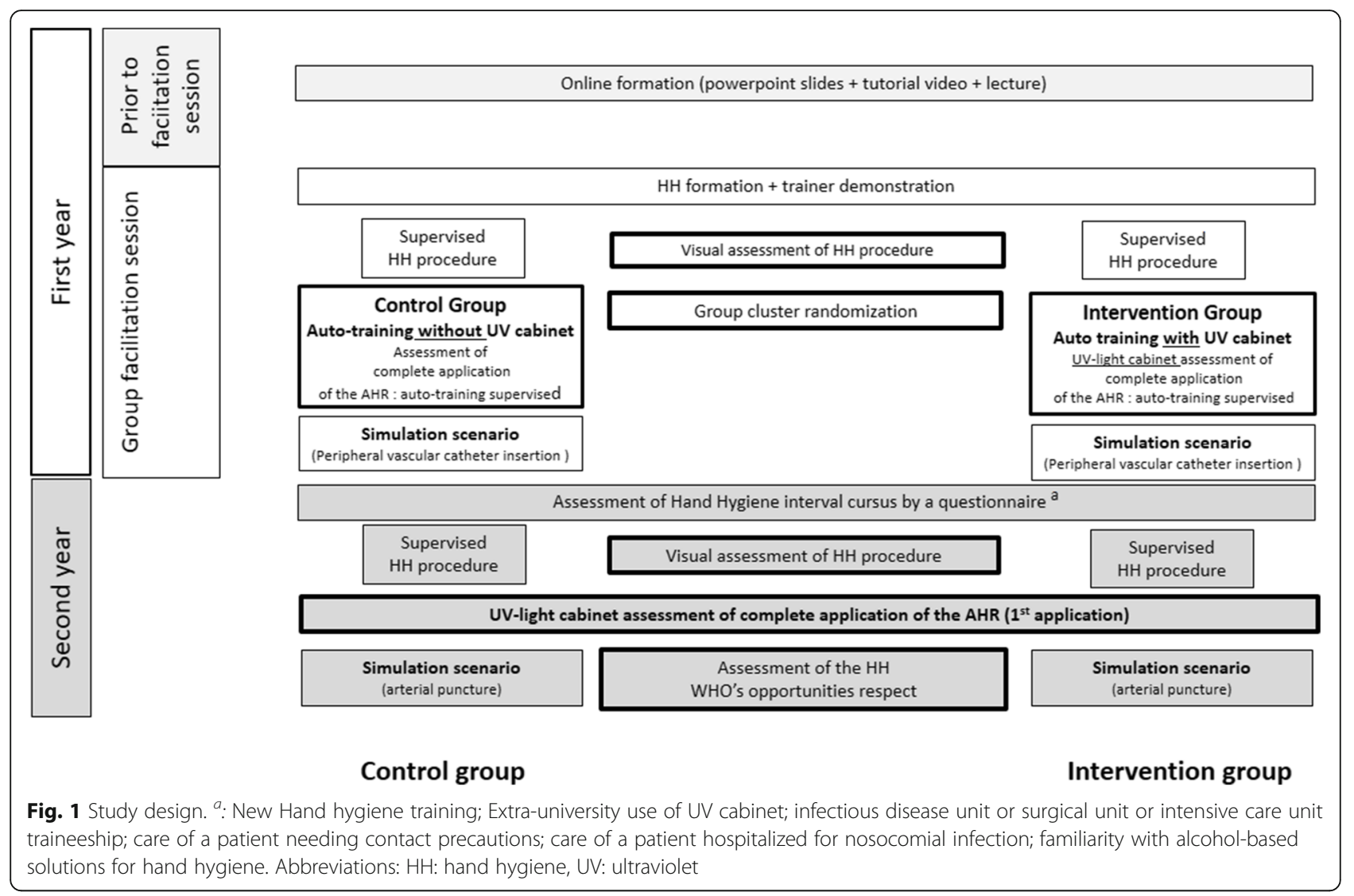

- In the intervention group: Student used a fluorescent AHR and UV cabinet (Daro UV Systems $\odot$, England) and supervised personal feedback. Each student received the same visual assessment as the control group, and after being shown their levels of completeness for AHR application under the UV light, the tutor recorded those results as complete or incomplete fluorescence of hands. The student was then given open access to the fluorescent AHR and the UV cabinet to repeat the WHO's handrubbing procedure, until both the tutor and the student judged their technique adequate.

- In the control group: Student handrubbed under the supervision of a tutor to assess their skills. The student was then given individualized recommendations and requested to handrub again until the tutor judged the completeness of AHR application according with the WHO's handrubbing procedure had been achieved.

Each students group underwent a computer-generated cluster randomization into the control group or the intervention group of the study just before the $\mathrm{HH}$ training.

On the second year, the program was the same but without new reminder and demonstration.
The medical students completed a questionnaire assessing their $\mathrm{HH}$ training and other potential confounding factors during the time interval between the two simulation sessions (new HH formation, experiences related to $\mathrm{HH}$ during training, supplementary experiences with the UV cabinet) (Additional File 2). Before the beginning of the scenario-based learning for an arterial puncture, each student was asked to perform the WHO's handrubbing procedure using the fluorescent AHR. The first year's tutor was replaced by another who was blinded to the assigned group. On a standardized document, the tutor visually assessed and recorded the quality of the WHO's handrubbing procedure; the completeness of hand hygiene by using UV light and finally their compliance with the WHO's opportunities for $\mathrm{HH}$ during the simulation session (Additional Files 3 and 4). Main endpoint of the study was defined as the ratio between the number of students with a complete fluorescence of hands and the total number of students in the group. The percentage of complete fluorescence of hands was compared between the intervention group and the control group.

A senior hygienist physician (NC) supervised the educational program. Students' training and evaluations were performed by four ICU physicians and four hygienist nurses, each with a $\mathrm{HH}$ post-graduate certification. These eight tutors were randomly assigned to a cluster. 
Preliminary meetings were conducted to standardize their evaluations of the WHO's HH procedure, the completeness of handrubbing under UV light and the compliance with the WHO's $\mathrm{HH}$ opportunities. The completeness of fluorescent AHR handrubbing was defined as fluorescence for all the surfaces of both hands and wrists. Compliance with $\mathrm{HH}$ opportunities was defined as the achievement of "the five moments for $\mathrm{HH}$ in health care" from the WHO during scenario-based learning (peripheral vascular catheter insertion and arterial puncture). A standardized document (Additional files 3 and 4) was used by tutors for the students' evaluations. In order to calibrate the evaluation procedure, the eight tutors jointly evaluated the first twenty-one students. The degree of agreement between the tutors was carried out using the Fleiss kappa coefficient to test the interrater reliability.

\section{Statistical analysis}

Quantitative variables were expressed as mean and standard deviations. Comparisons between control and intervention groups were performed using the Student ttest. Qualitative variables were expressed as the absolute value and percentage and compared by using the $\mathrm{Chi}^{2}$ Pearson test. Comparisons of the levels of completeness with AHR handrubbing and $\mathrm{HH}$ opportunities compliance between the first and the second-year data were tested using the Mc Nemar test. The associations between groups' allocation and qualitative variables were assessed using the $\mathrm{Chi}^{2}$ Pearson test. During the second year, a multinomial logistic regression procedure was performed to identify factors associated with the completeness of AHR handrubbing and the compliance with the WHO's $\mathrm{HH}$ opportunities using the control group as the reference. All of the variables with univariate test $p$ value $<0.20$ were included in the logistic regression model. Statistical analysis was conducted using SPSS v.20.0 (IBM, New York, USA). Two-sided $p$ value $<0.05$ was significant.

\section{Results}

\section{Characteristics of the students}

Among the 280 medical students eligible, 20 refused to participate, and 18 were ineligible because of missing data during their first or second year assessments. A total of $242(86 \%)$ students were included in the analysis, with 140 being in the intervention group (17 student groups). The remaining 102 were in the control group (15 student groups) (Fig. 2). Baseline characteristics of students are presented in Table 1. The Fleiss Kappa coefficient showed an important agreement between the tutors (0.74 (95\% CI: 0.66-0.82).
Main outcome: influence of supervised personal feedback on the completeness rate of AHR handrubbing

On the second year of pedagogical program, the 3rd degree students in the intervention group (supervised personal feedback with fluorescent AHR and UV cabinet) presented a higher rate of completeness for AHR application as compared with the 3rd degree students of control group $(60.0 \%$ versus $30.4 \% p<0.001$, intervention vs. control groups).

Other factors significantly associated with the complete AHR application included supplemental training in a hospital surgical unit $(p=0.011)$ as well as the use of the UV cabinet for extra-university $\mathrm{HH}$ training (hospital training) in the interval between the first and second modules $(p=0.004)$ (Table 2$)$. In the logistic regression model, the intervention group (those using the UV cabinet), women and the supplemental training in a hospital surgical unit were associated with an increased rate of complete application for the fluorescent-AHR (Table 2).

During the first year assessment (2nd degree students), only 43 of the 140 intervention group students $(30.7 \%)$ had a complete AHR handrubbing by using the alcohol solution under UV-light before supervised personal feedback (first assessment). The use of supervised personal feedback with fluorescent AHR and UV cabinet by 2nd degree medical students, double their rate of complete AHR handrubbing one year later (60.0 vs. $30.7 \%$, 2nd vs. 1st year). During the supervised personal feedback using UV cabinet and florescent AHR on the first year, the mean number of attempts before a complete AHR handrubbing achievement was $2.4( \pm 0.5)$. By protocol, the UV cabinet was not proposed to the control group on the first year, and their first rate of complete AHR handrubbing under UV light was only available during their second-year session. This rate was not significantly different from the first year intervention group assessment (before supervised personal feedback) $(n=31 / 102,30.4 \%$ versus $n=43 / 140,30.7 \%, p=0.96$ ).

Influence of supervised personal feedback on the level of completeness with the WHO's handrubbing technique After didactic theoretical training and visual demonstrations, the level of completeness for AHR handrubbing according with the WHO's HH procedure (AHR handrubbing technique) was $63.8 \%$ during the first year and $56.7 \%$ for the second year $(p=0.17)$. The groups' rates of compliant handrubbing of the WHO's $\mathrm{HH}$ procedure were similar between each compared year (Table 3).

\section{Influence of the UV auto-training on the handrubbing compliant with the WHO's HH opportunities}

During the second year, the rate of full compliance with the WHO's $\mathrm{HH}$ opportunities ("the five moments for 


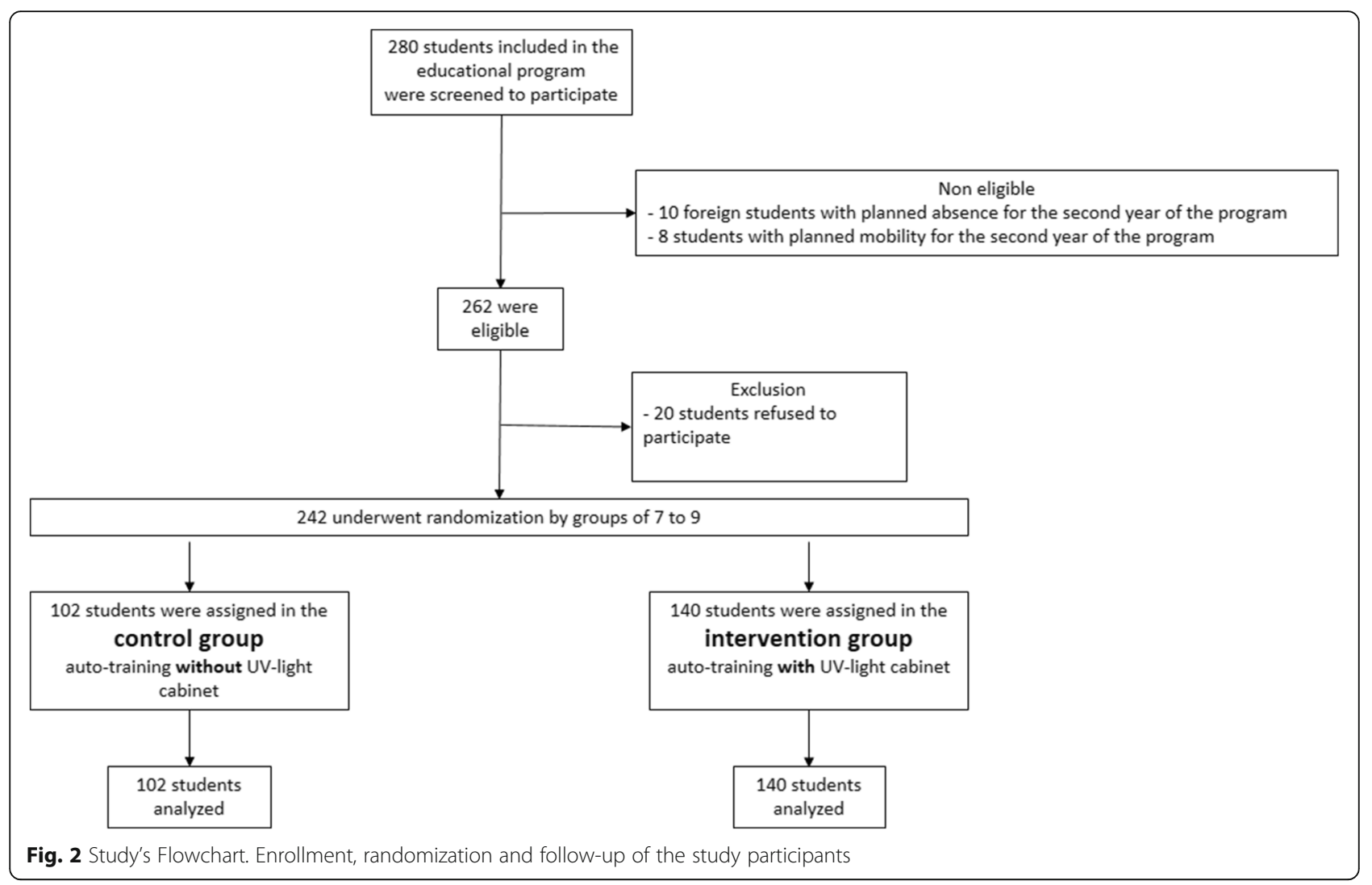

$\mathrm{HH}$ in health care") in the intervention group was $58.1 \%$ versus $42.4 \%$ in the control group $(p=0.018)$ (Table 4 ). Despite the lack of statistical significance, moment 1 of "WHO's five moments for $\mathrm{HH}$ in health care" (Before touching the patient), moment 3 (after the gloves) and moment 4 (after touching the patient) tend to be higher in the intervention group.

In the logistic regression, the intervention group was the only variable associated with complete compliance of the WHO's HH opportunities (Table 5). The HR for the intervention group was 1.88 (95\% CI: $1.10-3.21, p=0.02)$. Even after forcing the variable "women" in the model, the intervention group's full observance was significantly associated with the WHO's HH objectives (data not shown).

\section{Discussion}

With the participation of second and third year undergraduate medical students, we assessed if the $\mathrm{HH}$ was enhanced by the addition of supervised personal feedback with a fluorescent AHR and UV light inspection system (UV cabinet) during simulation scenario-based for training. Our results showed that when $\mathrm{HH}$ educational program include the use of a supervised personal feedback with a fluorescent AHR and UV light inspection system, the completeness with the AHR handrubbing and the compliance with WHO's $\mathrm{HH}$ opportunities were sustainably improved. We hypothesize that the use of fluorescent-AHR and UV-cabinet allows a direct personal feedback for the student. This feedback could have

Table 1 Baseline characteristics of the students

\begin{tabular}{lllll}
\hline Variable & All $n=242$ & Control group $n=102$ & Intervention group (Supervised personal feedback) $n=140$ & $p$-value \\
\hline Age \pm SD (years) & $21.2( \pm 2.2)$ & $21.0( \pm 1.8)$ & $21.0( \pm 2.5)$ & 0.36 \\
Female gender & $155(64.0)$ & $68(66.7)$ & $87(62.1)$ & \\
Hand hygiene personal experience before the study participation & 8.47 \\
-Previous hand hygiene formation & $13(5.4)$ & $5(4.9)$ & $2(1.4)$ & 0.78 \\
-Previous use of UV cabinet & $5(2.1)$ & $3(2.9)$ & $32(22.9)$ & 0.35 \\
-Previous use of alcoholic solution for HH & $57(23.6)$ & $25(24.5)$ & 0.65 \\
\hline
\end{tabular}


Table 2 Factors associated with the completeness of fluorescent alcohol-based handrubbing under ultraviolet-light (second year)

\begin{tabular}{|c|c|c|c|c|c|c|}
\hline \multirow[t]{2}{*}{ Variable } & $\begin{array}{l}\text { AHR Incomplete application } \\
(n=127)\end{array}$ & $\begin{array}{l}\text { AHR Complete application } \\
(n=115)\end{array}$ & $\begin{array}{l}p^{-} \\
\text {value }\end{array}$ & $\begin{array}{l}\text { Hazard } \\
\text { ratio }\end{array}$ & $\begin{array}{l}95 \% \text { confidence } \\
\text { interval }\end{array}$ & \multirow[t]{2}{*}{$\begin{array}{l}p^{\prime}- \\
\text { value }\end{array}$} \\
\hline & \multicolumn{3}{|l|}{ Univariate } & \multicolumn{2}{|c|}{ Logistic regression } & \\
\hline Age $\pm S D$ (years) & $21 \pm 1.7$ & $21 \pm 2.7$ & 0.68 & - & - & - \\
\hline Female gender & 59.1 & 69.6 & 0.08 & 1.86 & $1.02-3.37$ & 0.041 \\
\hline Personal feedback with UV cabinet & 44.1 & 73.0 & $\begin{array}{l}< \\
0.001\end{array}$ & 3.84 & $2.09-7.06$ & $\begin{array}{l}< \\
0.001\end{array}$ \\
\hline New Hand hygiene formation & 31.5 & 43.8 & 0.057 & 1.59 & $0.82-3.09$ & 0.17 \\
\hline Extra-university use of UV cabinet & 14.5 & 30.4 & 0.004 & 1.18 & $0.54-2.58$ & 0.67 \\
\hline Infectious disease unit traineeship & 19.4 & 16.1 & 0.51 & - & - & - \\
\hline Surgical unit traineeship & 54.5 & 70.5 & 0.011 & 1.85 & $1.00-3.43$ & 0.049 \\
\hline Intensive care unit traineeship & 10.5 & 13.4 & 0.49 & - & - & - \\
\hline $\begin{array}{l}\text { Care of a patient needing contact } \\
\text { precautions }\end{array}$ & 70.2 & 75.0 & 0.41 & - & - & - \\
\hline $\begin{array}{l}\text { Care of a patient hospitalized for } \\
\text { nosocomial infection }\end{array}$ & 16.1 & 15.3 & 0.86 & - & - & - \\
\hline Familiarity with alcoholic solution for $\mathrm{HH}$ & 75.0 & 82.1 & 0.17 & 1.44 & $0.73-2.86$ & 0.29 \\
\hline
\end{tabular}

Results are expressed as \%, except Age as mean ( \pm SD)

$p$-value: comparison by univariate test between the group with AHR Incomplete application versus the group with AHR Complete application

$p^{\prime}$-value: $p$-value by the multivariate logistic regression

Completeness of AHR handrubbing:

-AHR incomplete application corresponds to the presence of one or more areas without fluorescence on the hands and wrists of the students under UV-light

-AHR complete application corresponds to the absence of areas without fluorescence on the hands and wrists of the students under UV-light

Variables concerning the personal experience with hand hygiene between the first and the second year were collected on the second year as a questionnaire format from each 3rd degree student (see Additional file 2)

Abbreviations: AHR: Alcohol-based handrub, SD: standard deviation; UV: Ultraviolet

Table 3 Visual assessment of the World Health Organization's hand hygiene procedure on first year (baseline before training) and on second year (after training)

\begin{tabular}{|c|c|c|c|c|}
\hline & Variable & $\begin{array}{l}\text { Control } \\
\text { group } n= \\
102\end{array}$ & $\begin{array}{l}\text { Intervention group (Supervised } \\
\text { personal feedback) } n=140\end{array}$ & $\begin{array}{l}P \text { - } \\
\text { value }\end{array}$ \\
\hline \multirow{7}{*}{$\begin{array}{l}\text { YEAR } 1 \text { BASELINE } \\
\text { BEFORE TRAINING }\end{array}$} & Fully respected procedure (\%) & 58.9 & 66.9 & 0.22 \\
\hline & Palm to palm application (\%) & 97.8 & 98.6 & 0.66 \\
\hline & $\begin{array}{l}\text { Right palm over left dorsum with interlaced fingers application + } \\
\text { Palm to palm with fingers interlaced application (\%) }\end{array}$ & 92.2 & 95.0 & 0.40 \\
\hline & Backs of fingers to opposing palms with fingers interlocked (\%) & 85.6 & 89.9 & 0.32 \\
\hline & $\begin{array}{l}\text { Rotational rubbing of left thumb clasped in right palm and vice } \\
\text { versa (\%) }\end{array}$ & 86.7 & 91.4 & 0.26 \\
\hline & $\begin{array}{l}\text { Rotational rubbing, backwards and forwards with clasped fingers of } \\
\text { right hand in left palm and vice versa (\%) }\end{array}$ & 85.6 & 87.1 & 0.75 \\
\hline & Duration $\geq 20$ s $(\%)$ & 86.7 & 92.1 & 0.18 \\
\hline \multirow{7}{*}{$\begin{array}{l}\text { YEAR } 2 \text { AFTER TRAI } \\
\text { NING }\end{array}$} & Fully respected procedure (\%) & 50.5 & 61.3 & 0.09 \\
\hline & Palm to palm application (\%) & 98.0 & 97.1 & 0.66 \\
\hline & $\begin{array}{l}\text { Right palm over left dorsum with interlaced fingers application + } \\
\text { Palm to palm with fingers interlaced application (\%) }\end{array}$ & 95.0 & 90.5 & 0.19 \\
\hline & Backs of fingers to opposing palms with fingers interlocked (\%) & 71.3 & 80.3 & 0.11 \\
\hline & $\begin{array}{l}\text { Rotational rubbing of left thumb clasped in right palm and vice } \\
\text { versa (\%) }\end{array}$ & 79.2 & 82.5 & 0.52 \\
\hline & $\begin{array}{l}\text { Rotational rubbing, backwards and forwards with clasped fingers of } \\
\text { right hand in left palm and vice versa }(\%)\end{array}$ & 90.1 & 91.2 & 0.76 \\
\hline & Duration $\geq 20$ s (\%) & 92.1 & 96.3 & 0.16 \\
\hline
\end{tabular}


Table 4 Respect of the WHO's hand hygiene opportunities on second year ("the five moments for HH in health care")

\begin{tabular}{|c|c|c|c|}
\hline Variable & $\begin{array}{l}\text { Control group } n= \\
102\end{array}$ & $\begin{array}{l}\text { Intervention group (Supervised personal feedback) } \\
n=140\end{array}$ & $\begin{array}{l}p- \\
\text { value }\end{array}$ \\
\hline Full compliance (all the $\mathrm{HH}$ opportunities performed) (\%) & 42.4 & 58.1 & 0.018 \\
\hline $\begin{array}{l}\text { - Entry/before preparing the material (respect of moment 2) } \\
(\%)\end{array}$ & 100 & 100 & - \\
\hline - Before touching the patient (respect of moment 1) (\%) & 77.8 & 85.3 & 0.14 \\
\hline - Before glove for puncture (respect of moment 2) (\%) & 80.9 & 79.8 & 0.84 \\
\hline - After gloves for puncture (respect of moment 3) & 74.7 & 80.9 & 0.26 \\
\hline $\begin{array}{l}\text { - After gloves for material evacuation (respect of moment 3) } \\
(\%)\end{array}$ & 76.8 & 81.6 & 0.36 \\
\hline $\begin{array}{l}\text { - After touching the patient before exit (respect of moment } \\
\text { 4) (\%) }\end{array}$ & 75.8 & 84.6 & 0.09 \\
\hline \multicolumn{4}{|c|}{$\begin{array}{l}\text {-value: chi-2 Pearson test } \\
\text { The moments refer to the WHO's indications for hand hygiene ("the five moments for HH in health care") } \\
\text { Compliance at the entry is } 100 \% \text { in both groups because assessment of application of the AHR under UV light was done at this step } \\
\text { Each student was evaluated during the scenario-based learning for an arterial puncture (first attempt). On a standardized document, the tutor visually assessed } \\
\text { and recorded their respect of the WHO's hand hygiene opportunities during the simulation session } \\
\text { Full observance corresponded that the student performed all (6) the HH opportunities }\end{array}$} \\
\hline
\end{tabular}

an important impact on the memorization process for the handrubbing technique allowing the complete application of the AHR. With the UV-cabinet, there would be a playful aspect which could facilitate the learning and memorization process. Further studies are needed to investigate this hypothesis.

Kaur et al underlined a lack of a rigorous evaluation of tools and educational material for medical students [8]. In our study, the presence of a control group allowed individualization of the proper effect of the intervention group inside our multimodal educational program.
Despite this multimodal program, overall, there was a low rate of completeness of AHR handrubbing (60\% in the intervention group and $30.4 \%$ in the control group). Our hypothesis was that long-term outcome evaluations revealed a progressive decline in compliant handrubbing and regularly supervised personal feedback would be needed to receive the procedure's benefits.

Some studies previously reported using supervised personal feedback with UV light inspection systems in the medical students' training programs $[11,12,16]$. In all these studies, the absence of a control group did not allow individualizing the proper effect of feedback with

Table 5 Factors associated with the respect of the WHO's hand hygiene opportunities ("the five moments for HH in health care") on second year

\begin{tabular}{|c|c|c|c|c|c|c|}
\hline \multirow[t]{2}{*}{ Variable } & $\begin{array}{l}\text { Incomplete respect }(n= \\
117)\end{array}$ & $\begin{array}{l}\text { Full respect }(n= \\
125)\end{array}$ & $\begin{array}{l}p^{-} \\
\text {value }\end{array}$ & $\begin{array}{l}\text { Hazard } \\
\text { ratio }\end{array}$ & $\begin{array}{l}95 \% \text { confidence } \\
\text { interval }\end{array}$ & \multirow[t]{2}{*}{$\begin{array}{l}p^{\prime}- \\
\text { value }\end{array}$} \\
\hline & \multicolumn{3}{|l|}{ Univariate } & \multicolumn{2}{|c|}{ Logistic regression } & \\
\hline Personal feedback with UV cabinet (\%) & 50.0 & 65.3 & 0.016 & 1.88 & $1.10-3.21$ & 0.02 \\
\hline Female gender (\%) & 60.5 & 67.8 & 0.247 & - & - & - \\
\hline Age \pm SD (years) & $21 \pm 2.6$ & $21 \pm 1.8$ & 0.254 & - & - & - \\
\hline New Hand hygiene formation (\%) & 41.6 & 33.1 & 0.179 & 0.70 & $0.40-3.20$ & 0.20 \\
\hline Extra-university use of UV cabinet (\%) & 22.1 & 21.2 & 0.863 & - & - & - \\
\hline Infectious disease unit traineeship (\%) & 17.7 & 17.8 & 0.985 & - & - & - \\
\hline Surgical unit traineeship (\%) & 66.1 & 58.5 & 0.235 & - & - & - \\
\hline Intensive care unit traineeship (\%) & 11.5 & 12.7 & 0.779 & - & - & - \\
\hline Care of a patient needing contact precautions (\%) & 71.7 & 72.9 & 0.839 & - & - & - \\
\hline $\begin{array}{l}\text { Care of a patient hospitalized for nosocomial } \\
\text { infection (\%) }\end{array}$ & 17.7 & 13.7 & 0.401 & - & - & - \\
\hline Familiarity with alcoholic solution for $\mathrm{HH}(\%)$ & 73.5 & 82.2 & 0.109 & 0.55 & $0.88-3.18$ & 0.11 \\
\hline
\end{tabular}

$p$ value = comparison by univariate test between the group with incomplete respect versus the group with complete respect of the WHO's HH opportunities $p^{\prime}$-value: $p$-value by the multivariate logistic regression

Abbreviations: SD standard deviation, UV Ultraviolet, HH Hand hygiene 
UV within the rest of the training program. Scheithauer et al. observed that third-year students receiving timely training of $\mathrm{HH}$ had an immediate $(22 \%)$ reduction in incomplete handrubbing after monitoring with the UV cabinet [11]. The baseline rate of completeness of AHR handrubbing after the first UV training was $29 \%$. This was similar to the baseline rate observed in the first-year intervention group (30.7\%), with ongoing training yielding a positive impact on outcomes. Lehotsky et al. observed that third-year students in the basic surgical techniques class used a UV based system for assessment and auto feedback immediately after receiving $\mathrm{HH}$ education [16]. This study reported a completeness rate of handrubbing of $61.8 \%$, which is also very similar to the rate observed during the second-year intervention group (60\%). Vanyolos et al. observed 285 medical students who were included in an educational program on "basic surgical techniques" which included a lecture on $\mathrm{HH}$ and a training with groups of 5 to 7 students [12]. The completeness rate of handrubbing wasn't recorded immediately after the first application. The authors reported a rate of complete AHR application of $51.4 \%$ at week 14 and $74.3 \%$ at week 10 after the intervention [12].

Unexpectedly, when the tutor visually assessed the quality of the WHO's handrubbing procedure without UV cabinet, the difference in the completeness rate of handrubbing in the second-year students between the two groups was not significant (Tables $3,61.3 \%$ versus $50.5 \%, p=0.096$; intervention vs. control groups, respectively). This may be due to a lack of sensibility of single visual assessment without UV light to detect the forgotten steps of the WHO's HH procedure. It may also be explained by integrating the missed skin areas despite correct procedures and consequently, the addition of supplementary movements to reach the completeness of handrubbing. The WHO's $\mathrm{HH}$ procedure was designed to ensure homogenous hand surface coverage by applied AHR. However, it is not user friendly and recent studies question its adaptability. Indeed, when monitored, $\mathrm{HCW}$ compliance with all six steps of the procedure, is low with the last steps (fingertips and thumbs) being the most frequently missed [16-18]. Alternative methods with equivalent bacterial effectiveness have been proposed $[19,20]$. However, more research is needed in order to validate this conclusion.

At the beginning of the second simulation session, there was a non-significant trend towards a decrease in the rate of complete compliance of the $\mathrm{HH}$ procedure in both groups when no technique review had been proposed. This suggests that, as with other HCWs, regular training is obligatory to comply with $\mathrm{HH}$ practices [21].

Our results suggested that the intervention group had a positive influence on compliant handrubbing with the
WHO's HH opportunities during the simulation scenario-based learning. This was in accordance with the Higgins et al study, which reported a sustained improvement of $\mathrm{HH}$ compliant handrubbing from 20 to $58 \%$ within a year after implementation of a personal feedback tool using gaming technology with an automated auditing and training unit [22]. This was however not confirmed in the Kwok et al. study [23]. This effect may be related to the role of personal feedback in awareness of HH's importance to prevent cross transmission.

Our study has several limitations. Firstly, since we wanted to ensure that control clusters wouldn't benefit from any feedback with the UV cabinet, we didn't assess the completeness of their WHO's $\mathrm{HH}$ procedure with UV cabinets during the first year. Consequently, their first completeness rate for the handrubbing under a UV light was only available during their second year. This rate was not significantly different from the intervention group's rate (before supervised personal feedback) evaluated first year (data not shown). Secondly, our UV assessment cabinet didn't provide photo storage after fluorescent AHR use for a retrospective, exhaustive analysis of the missed locations with a planimetry system. Thus, we chose to divide the AHR application as complete or not, since we could not study the relationship between the steps forgotten during the $\mathrm{HH}$ procedure and the areas missed. This information could have helped us better precisely understand the change in the AHR techniques induced by the UV lamp feedback. Thirdly, the personal experiences of students between the 1 st and the 2nd year impacted the study outcome and represent confounding factors. On the 2 nd year, we asked the students about their personal feedback for these confounding factors. However, despite our methodological cautions and the multivariate analysis, we cannot exclude that the students forgot to specify some confounding factors (memory bias). Moreover, our study did not allow to know if the students who performed AHR complete application more often remember extra-university use of UV cabinet, or, if the students using the extra-university of UV cabinet performed AHR complete application better. Finally, whether or not our results can be extrapolated in healthcare settings is speculative because students have a higher exposure to negative role models, as a poor compliance of the WHO's HH recommendations by some heath care workers.

\section{Conclusion}

A key component of the undergraduate medical students' training for hand hygiene should include supervised personal feedback with UV cabinets in handrubbing procedures to improve theirs compliance rate with WHO's recommendations (handrubbing procedure and hand hygiene opportunities). 


\section{Supplementary information}

Supplementary information accompanies this paper at https://doi.org/10. 1186/s13756-020-00808-4.

Additional file 1. World health organization's hand hygiene procedure with Alcohol-based handrub.

Additional file 2. Second year questionnaire about hand hygiene cursus in the interval between the two facilitation sessions.

Additional file 3. Standardized assessment form for Alcohol-based handrub application

Additional file 4. Standardized assessment form for Alcohol-based handrub opportunities.

\section{Abbreviations}

AHR: Alcohol-based handrubs; Cl: Confidence interval; $\mathrm{HH}$ : Hand hygiene; IQR: Interquartile range; UV: Utraviolet; UVc: Ultraviolet cabinet; WHO: World Health Organization

\section{Acknowledgements}

The authors wish to thank all the participating students.

\section{Authors' contributions}

SD, SL, SV, PN, MSB, FD, DB, EP, IJ, SLF, GG, GL, LP, NC, JMF JMF, SD, LP, SL, $N C$ and $G G$ designed the work. NC supervised the educational program. SV, $P N, M S B, F D, S L, D B, E P$ and IJ collected the data and were the tutors of the students. SD, SL and JMF analyzed, interpreted the data and wrote the manuscript. LP and GL revised the manuscript. All authors read and approved the final manuscript.

\section{Funding}

None.

\section{Availability of data and materials}

The datasets used and analyzed during the current study are available from the corresponding author on reasonable request.

\section{Ethics approval and consent to participate}

Our Institutional Review Board approved the study. All participants received written information on the study and provided us with written consent to participate.

\section{Consent for publication}

Not applicable.

\section{Competing interests}

The authors declare that they have no competing interests.

\section{Author details}

${ }^{1}$ Médecine Intensive Réanimation, Assistance Publique Hôpitaux de Marseille, CHU Nord, Chemin des Bourrely, 13015 Marseille, France. ${ }^{2}$ Service d'Aide Médicale Urgente (SAMU), Assistance Publique Hôpitaux de Marseille, CHU Timone, Marseille, France. ${ }^{3}$ Département d'Anesthésie Réanimation, Assistance Publique Hôpitaux de Marseille, CHU Timone, Marseille, France. ${ }^{4}$ Service d'Accueil des Urgences, Assistance Publique Hôpitaux de Marseille CHU Nord, Marseille, France. ${ }^{5}$ Comité de Lutte Contre les Infections Nosocomiales (CLIN), Assistance Publique Hôpitaux de Marseille, CHU Nord, Marseille, France. ${ }^{6}$ Faculté de Médecine de Marseille, Aix Marseille University, Marseille, France. ${ }^{7}$ Faculté de Médecine de Marseille, EA 3279, CEReSS Health Service Research and Quality of life Center, Aix Marseille University, Marseille, France.

Received: 28 May 2020 Accepted: 21 August 2020 Published online: 03 September 2020

\section{References}

1. Feather A, Stone SP, Wessier A, Boursicot KA, Pratt C. "Now please wash your hands": the handwashing behaviour of final MBBS candidates. J Hosp Infect. 2000;45:62-4.
2. Mann CM, Wood A. How much do medical students know about infection control? J Hosp Infect. 2006:64:366-70.

3. Graf K, Chaberny IF, Vonberg R-P. Beliefs about hand hygiene: a survey in medical students in their first clinical year. Am J Infect Control. 2011;39:885-8.

4. Roberto MS, Mearns K, Silva SA. Social and moral norm differences among Portuguese 1st and 6th year medical students towards their intention to comply with hand hygiene. Psychol Health Med. 2012;17:408-16.

5. Hunt DCE, Mohammudally A, Stone SP, Dacre J. Hand-hygiene behaviour, attitudes and beliefs in first year clinical medical students. J Hosp Infect. 2005;59:371-3.

6. Kaur $\mathrm{R}$, Razee $\mathrm{H}$, Seale $\mathrm{H}$. Setting the right foundations: improving the approach used to teach concepts of hand hygiene to medical students. J Hosp Infect. 2017:95:355-8.

7. Kaur R, Razee H, Seale H. Facilitators and barriers around teaching concepts of hand hygiene to undergraduate medical students. J Hosp Infect. 2014;88:28-33.

8. Kaur R, Razee $H$, Seale $H$. Exploring the approaches used to teach concepts of hand hygiene to Australian medical students. J Infect Prev. 2015;16:162-6.

9. World Health Organization, editor. WHO guidelines on hand hygiene in health care: first global patient safety challenge: clean care is safer care. Geneva, Switzerland: World Health Organization, Patient Safety; 2009.

10. Hautemanière A, Diguio N, Daval MC, Hunter PR, Hartemann P. Short-term assessment of training of medical students in the use of alcohol-based hand rub using fluorescent-labeled hand rub and skin hydration measurements. Am J Infect Control. 2009;37:338-40.

11. Scheithauer S, Haefner H, Schwanz T, Lopez-Gonzalez L, Bank C, SchulzeRöbbecke $\mathrm{R}$, et al. Hand hygiene in medical students: performance, education and knowledge. Int J Hyg Environ Health. 2012;215:536-9.

12. Vanyolos E, Peto K, Viszlai A, Miko I, Furka I, Nemeth N, et al. Usage of ultraviolet test method for monitoring the efficacy of surgical hand rub technique among medical students. J Surg Educ. 2015;72:530-5.

13. Lehotsky A, Szilágyi L, Ferenci T, Kovács L, Pethes R, Wéber G, et al. Quantitative impact of direct, personal feedback on hand hygiene technique. J Hosp Infect. 2015:91:81-4.

14. WHO Library Cataloguing-in-Publication Data. Hand hygiene technical reference manual: to be used by health-care workers, trainers and observers of hand hygiene practices 2009. https://apps.who.int/iris/bitstream/handle/1 0665/44196/9789241598606_eng.pdf;jsessionid=87E2DE315A93702F342E6E3 OD269DDBD? sequence=1. Accessed September 7, 2017.

15. WHO Hand Hygiene VIDEOS in The New England Journal of Medicine in YOUR language. WHO n.d. http://www.who.int/gpsc/5may/hand_hygiene_ video/en/. Accessed September 7, 2017.

16. Lehotsky Á, Szilágyi L, Demeter-Iclănzan A, Haidegger T, Wéber G. Education of hand rubbing technique to prospective medical staff, employing UV-based digital imaging technology. Acta Microbiol Immunol Hung. 2016:63:217-28.

17. Tschudin-Sutter S, Sepulcri D, Dangel M, Schuhmacher H, Widmer AF. Compliance with the World Health Organization hand hygiene technique: a prospective observational study. Infect Control Hosp Epidemiol. 2015;36:482-3.

18. Stewardson AJ, Iten A, Camus V, Gayet-Ageron A, Caulfield D, Lacey G, et al. Efficacy of a new educational tool to improve Handrubbing technique amongst healthcare workers: a controlled, before-after study. PLoS One. 2014:9:e105866

19. Tschudin-Sutter S, Rotter ML, Frei R, Nogarth D, Häusermann P, Stranden A, et al. Simplifying the WHO 'how to hand rub' technique: three steps are as effective as 102 six-results from an experimental randomized crossover trial. Clin Microbiol Infect 2017;23:409.e1-409.e4

20. Pires D, Bellissimo-Rodrigues F, Soule H, Gayet-Ageron A, Pittet D. Revisiting the WHO "how to Handrub" hand hygiene technique: fingertips first? Infect Control Hosp Epidemiol. 2017;38:230-3

21. Whitby M, McLaws M-L, Slater K, Tong E, Johnson B. Three successful interventions in health care workers that improve compliance with hand hygiene: is sustained replication possible? Am J Infect Control. 2008:36:349-55.

22. Higgins A, Hannan MM. Improved hand hygiene technique and compliance in healthcare workers using gaming technology. J Hosp Infect. 2013;84:32-7.

23. Kwok YLA, Callard M, McLaws M-L. An automated hand hygiene training system improves hand hygiene technique but not compliance. Am J Infect Control. 2015:43:821-5.

\section{Publisher's Note}

Springer Nature remains neutral with regard to jurisdictional claims in published maps and institutional affiliations. 